DOI: $10.12731 / 2306-1561-2013-4-5$

\title{
MODEL OF FORMATION AND CONTROL OF ADMINISTRATIVE ACTION
}

\author{
Ataeva S.K., Beliyanskiy A.V., Chugunova D.N.
}

\section{Abstract}

This paper proposes an approach to the formation and control of management activities at industrial enterprises. A structure model of organization management manager many processes as a result of the implementation of management measures.

Keywords: management, modeling, process model, scheduling theory, automated control systems.

\section{УДК 681.3}

\section{МОДЕЛЬ ФОРМИРОВАНИЯ И КОНТРОЛЯ УПРАВЛЕНЧЕСКИХ МЕРОПРИЯТИЙ}

\section{Атаева С.К., Белянский А.В., Чугунова Д.Н.}

\section{Аннотация}

B статье предложен подход $\kappa$ формированию $u$ контролю управленческих мероприятий на промышленных предприятий. Предложена структура модели организации управления руководителем множеством процессов в результате реализации управленческих мероприятий.

Ключевые слова: управление, моделирование, прочессная модель, информационная среда, автоматизированные системы управления.

В общем случае на практике процесс управления реализует как плановые, так и дополнительные мероприятия. Для их временного согласования обычно руководитель создает оперативные планы-сценарии управленческих мероприятий (УМ) [1].

Для позитивной оценки влияния автоматизированной системы поддержки управленческих решений на организацию работы руководителя, необходимо обеспечение регулярного отслеживания динамики управленческих процессов, их ситуационный анализ и оценка текущего состояния для формирования решений по срокам проведения соответствующих мероприятий [1 - 9]. При моделировании специфики поведения руководителей в ходе проведения управленческих мероприятий необходимо учитывать, что параллельно с управляемым процессом реализуется управляющий процесс. В ходе наблюдения за управляемыми процессами, как правило, через посредничество руководитель формирует управленческие мероприятия, которые 
различаются по сложности и направленности. При необходимости достаточно сложные мероприятия могут быть разделены на субмероприятия, а их выполнение разнесено во времени. В промежутках между субмероприятиями руководитель организует другие управленческие мероприятия.

Структура модели организации управления руководителем множеством процессов в результате реализации управленческих мероприятий (УМ) приведена на рисунке 1.

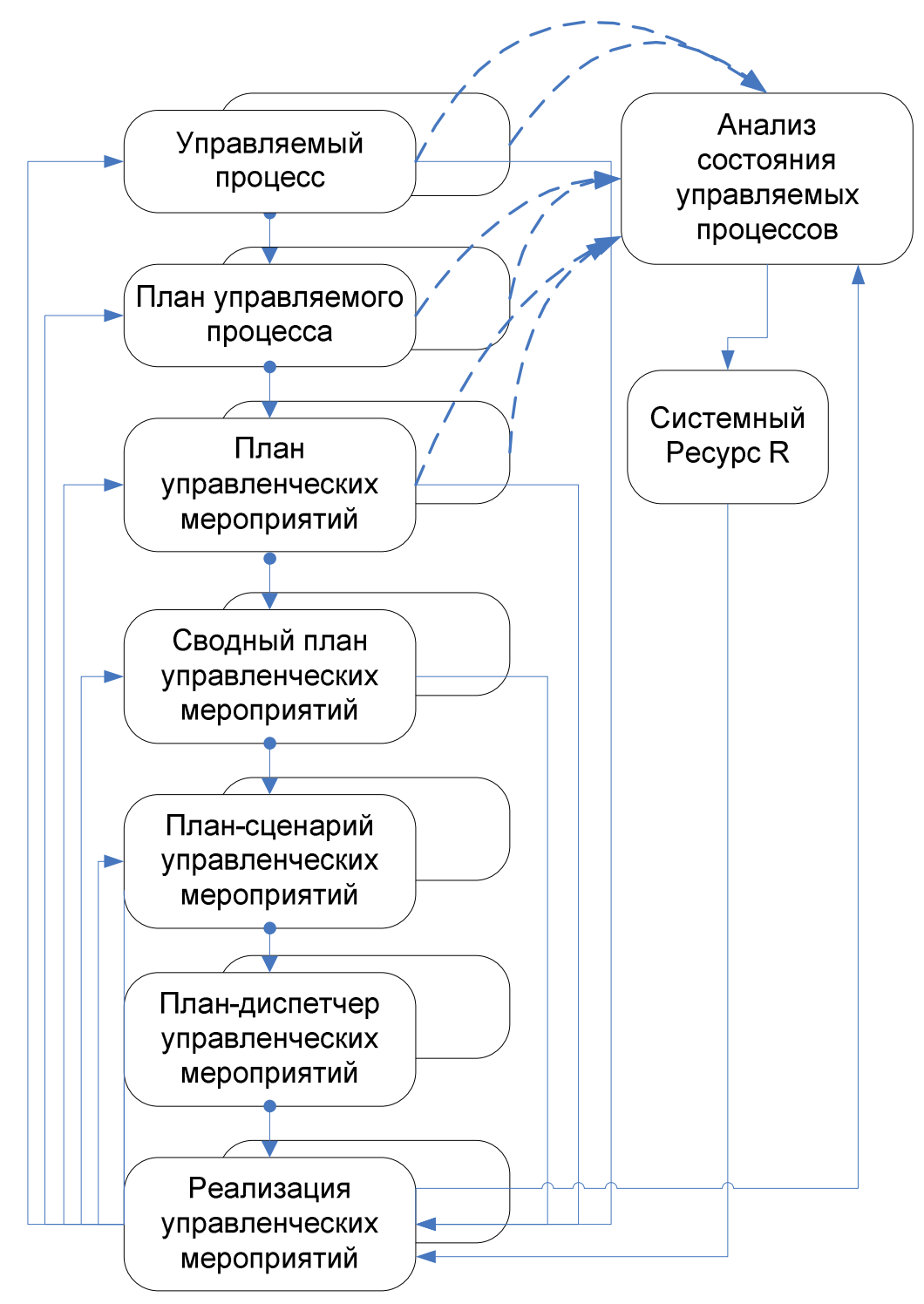

Рисунок 1 - Структурная схема управленческой деятельности

На схеме изображены:

- управляемые процессы $Y_{i d_{(v-1)}}(t)(i=\overline{1, l})$ - I процессов, которые одновременно протекают и находятся под постоянным наблюдением и управлением руководства объединения, среди которых имеют место как полностью независимые, так и частично зависимые; 
- планы управляемых процессов

$$
P_{\text {Yid }_{(\mathrm{v}-1)}}(t)(i=\overline{i, l})
$$

- согласуются с сетевой моделью и детализируются по каждому этапу с учетом возможных задержек и непредвиденных расходов предыдущих этапов;

- планы УМ $P_{m i}(i=\overline{1, l})$ - также формируются с учетом календарных планов сетевой модели и детализации состояний управляемых процессов, направленные на организационные аспекты реализации программы управленческих мероприятий;

- программа анализа характеристик и параметров управляемых процессов, которая выполняет действия

$$
\left.A_{i}: a_{i} \mid t_{j}, Y_{i d_{(v-1) j}^{j}}, P_{Y_{i d}(v-1) j}, k_{i j}\right\rfloor \rightarrow e_{i j}(i=\overline{1, l}),
$$

- каждое из которых преобразует моменты времени tj для текущего состояния, Yij, управляемого процесса, Руіј плана по обобщенной системе критериев kij в оценочные значения показателей еij, а также формирующая интегральную характеристику обобщенного процесса, представляющего объединение

$$
B: \beta\left\lfloor e_{i j}, C_{j}\right\rfloor \rightarrow E_{j}
$$

- в зависимости от оценки состояний и содержания агрегированной цели $\mathrm{Cj}$ формируемой на основании подцелей сіј в моменты времени ti:

$$
\left.\Gamma: \gamma \mid c_{i j}\right\rfloor \rightarrow C_{j}
$$

- обобщенный план УМ

$$
P_{m}=\bigcup_{i} P_{\text {mid }_{(v-1)}}
$$

- формируется на основании формального объединения всех планов управленческих мероприятий для управляемых процессов;

- план-сценарий УМ Рт , является подмножеством обобщенного плана УМ (4), относящийся к строго определенному промежутку времени

$$
\tau \times P_{m} \rightarrow P_{m \tau}
$$

- план-диспетчер УМ $P_{d_{d_{v}}^{k} \text { представляет расписание на период d выполнения }}$ УМ и создается как подвыборка плана-сценария $\operatorname{Pm} \tau$ на дату $\mathrm{dv}$

$$
d_{v} \times P_{m \tau} \rightarrow P_{m \tau d_{v}}
$$

- и последующего разнесения УМ по времени $(\mathrm{k}=1,2, \ldots)$

$$
H: \eta\left[P_{m \tau d_{v}} ; t_{d_{\tau}}^{k}\right] \rightarrow P_{m t_{d_{v}}^{k}}
$$

- peсурс R (материальные ресурсы, людские, свободные производственные мощности, финансы и т.д.), является резервом, направленным на возможность корректировки управляющих процессов; 
- процесс реализации УМ представляет действия руководителя, которые выполняются, как правило, в установленных рамках. В этих пределах реализуются процедуры оперативного управления, которые ориентируются на выполнение запланированных УМ в каждый момент времени $t_{d_{\tau}}^{k} t_{d_{\tau}}^{k} \times P_{m t_{d_{v}}^{k}}$, на основании которого:

- оценивается текущее состояние управляемого процесса (1) и формируется обобщенная оценка состояния совокупности всех процессов (2);

- реализуется управляющее воздействие;

- корректируется и редактируется сам управляемый процесс;

- выполняется коррекция плана управляемого процесса;

- корректируется план УМ и т.д.

Таким образом, предложенная модель формирования управленческих мероприятий направлена на постоянный мониторинг и коррекцию управленческих мероприятий для соблюдения сформированных планов реализации программы стратегического развития.

Для предлагаемой системы моделей и функций управления разработана архитектура программно-моделирующего комплекса, а также предложена структура информационных потоков и программного обеспечения (ПО) в системе подготовки планов стратегического развития (рисунок 2).

Разработаны алгоритмы реализации отдельных этапов стратегического планирования, включающие структуры данных для моделирования рыночной среды, систему показателей финансовой деятельности, данные для мониторинга и др., которые служат для поддержки принятия управленческих решений. 


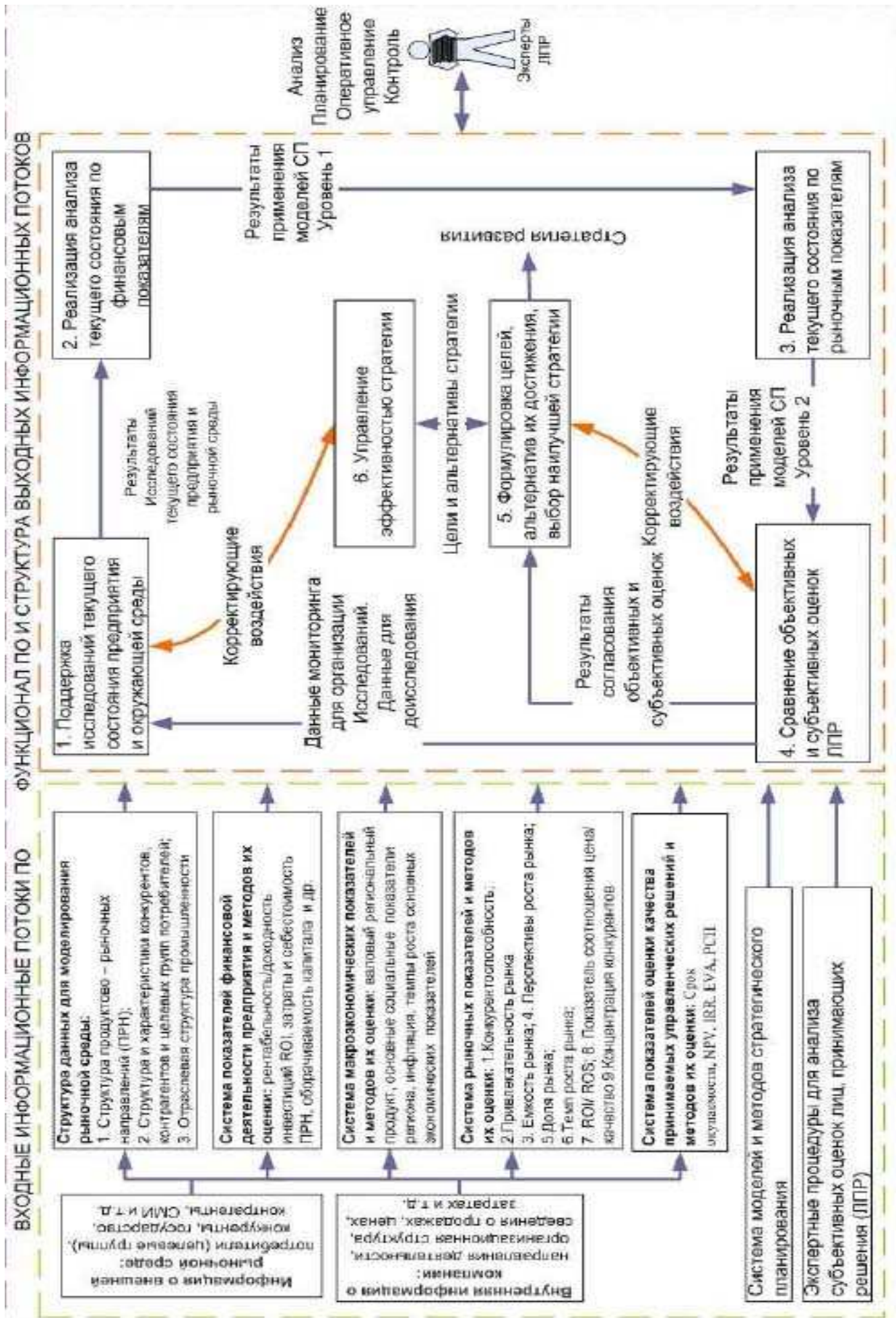

Рисунок 2 - Структура информационных потоков и ПО в системе подготовки планов стратегического развития

\section{Список информационных источников}

[1] Николаев А.Б. Информационные технологии в менеджменте и транспортной логистике: учебное пособие / А.Б. Николаев, А.В. Остроух. - Saint-Louis, MO, 
USA: Publishing House Science and Innovation Center, 2013. - 254 c. - ISBN 978-0615-67110-9.

[2] Остроух А.В. Разработка информационно-аналитической системы мониторинга технологических процессов предприятия автомобильной промышленности / А.В. Остроух, Юань Тянь // В мире научных открытий - Красноярск: Научноинновационный центр, 2013. - №8.2 (44). - С. 191-205.

[3] Остроух, А.В. Информационные технологии в научной и производственной деятельности / [ред. А.В. Остроух] - М: ООО "Техполиграфцентр", 2011. - 240 с. ISBN 978-5-94385-056-1.

[4] Суркова Н.Е., Угарова Ю.Н. Организация работы ит-подразделения в холдинговых структурах // Автоматизация и управление в технических системах. - 2013. - № 1(3); URL: auts.esrae.ru/3-59 (дата обращения: 31.10.2013).

[5] Тянь Юань. Мониторинг процесса производства сухих строительных смесей / А.В. Остроух, Вэй Пьо Аунг, Юань Тянь // Наука и образование в XXI веке: Теоретические и прикладные вопросы науки и образования: сб. науч. тр. по матлам Междунар. науч. - практ. конф. 30 сентября 2013 г.: Часть 1. - Тамбов: ТРОО «Бизнес-Наука-Общество», 2013. - С. 138-140.

[6] Тянь Юань. Мониторинг технологического процесса производства керамического кирпича / А.В. Остроух, Р.P. Чаудхари, Юань Тянь // Наука и образование в XXI веке: Теоретические и прикладные вопросы науки и образования: сб. науч. тр. по мат-лам Междунар. науч. - практ. конф. 30 сентября 2013 г.: Часть 1. - Тамбов: ТРОО «Бизнес-Наука-Общество», 2013. - С. 140-143.

[7] Тянь Юань. Интеграция компонентов системы мониторинга /А.В. Остроух, Юань Тянь // Молодой ученый. - Чита: ООО «Издательство Молодой ученый», 2013. №10. - С. 182-185.

[8] Тянь Юань. Современные методы и подходы к построению систем управления производственно-технологической деятельностью промышленных предприятий / А.В. Остроух, Юань Тянь // Автоматизация и управление в технических системах. - 2013. - № 1(3); URL: auts.esrae.ru/3-53 (дата обращения: 24.09.2013). 